
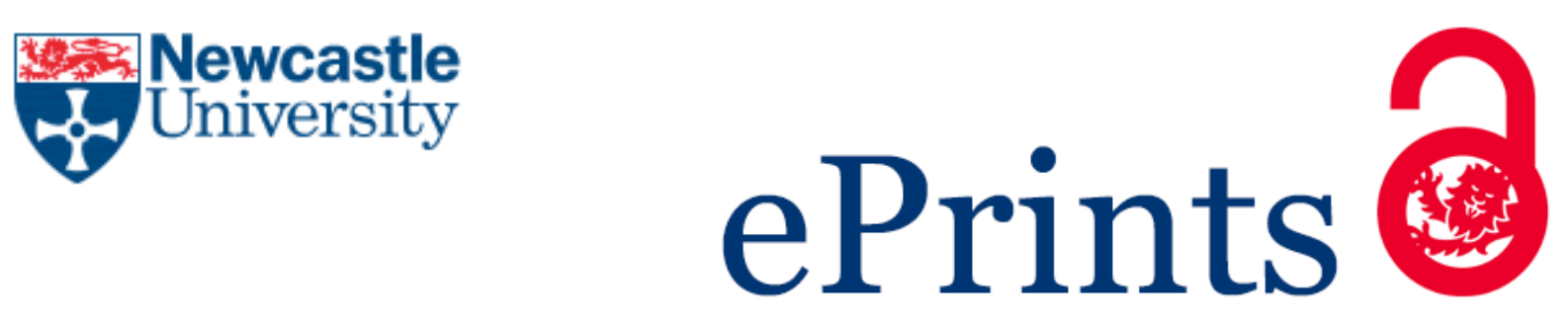

Grainger MJ, Aramyan L, Logatchevac K, Piras S, Righi S, Settib M, Vittuari M, Stewart GB.

The use of systems models to identify food waste drivers.

Global Food Security 2018

DOI: https://doi.org/10.1016/j.gfs.2017.12.005

\title{
Copyright:
}

(C) 2018. This manuscript version is made available under the CC-BY-NC-ND 4.0 license

DOI link to article:

https://doi.org/10.1016/i.gfs.2017.12.005

Date deposited:

$02 / 02 / 2018$

Embargo release date:

01 February 2019

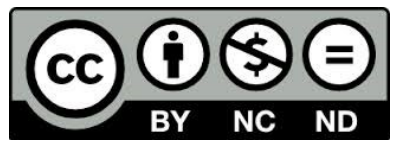

This work is licensed under a

Creative Commons Attribution-NonCommercial-NoDerivatives 4.0 International licence 


\section{The use of systems models to identify food waste drivers}

\section{Abstract}

4 In developed countries, the largest share of food waste is produced at household level. Most

5 studies on consumers' food waste use models that identify covariates as significant when in

6 fact they may not be, particularly where these models use many variables. Here, using EU-

7 level Eurobarometer data from 2013, we use alternative analytical methods that avoid these

8 problems (Bayesian Networks) to identify the impact of household characteristics and other

9 variables on self-assessed food waste. Our analysis confirmed that the country, the age of the 10 respondent, the status (student/non-student), and a belief that the family wastes too much are 11 related to the level of self-assessed food waste. But we found no evidence that waste behav12 iours differ between people living in urban and rural areas, and little support of a difference 13 between genders. Households from lower-income EU countries (e.g. Portugal, Greece, Bul14 garia, Cyprus and Latvia), as well as students and young adults tend to report higher levels of 15 food waste. Hence, the adoption of an EU strategy based on the concept of subsidiarity, and 16 of country-level policy measures targeting different age groups is suggested. Furthermore, 17 our analysis shows that policy makers need to be wary of relying on analysis based on large 18 datasets that do not control for false-positives, particularly when sample sizes are small.

\section{Keywords}

20 Consumers, decision modelling, household food waste, European Union 


\section{Introduction}

Food waste represents a major challenge for responsible business and consumer behaviours, and for sustainable food value chains (FAO 2011; FAO 2013). For this reason, the Sustainable Development Goal 12, Target 12.3 calls for halving per capita food waste and reducing food losses by 2030 (UNEP 2016). Also the EU has made the reduction of food waste a priority (European Commission 2015). The waste produced at household level is thought to be responsible for the largest proportion of all food wasted in developed countries (Parfitt et al. 2010). Stenmarck et al. (2016) estimated food waste in the 28 EU countries (extrapolated from data for 11 countries) at $87.6 \pm 13.7(95 \% \mathrm{CI})$ million tonnes, with $46.5 \pm 4.4(95 \% \mathrm{CI})$ million tonnes coming from households. This means that between 46.7 and $63.5 \%$ of the total EU food waste comes from households.

Food waste occurring at household level has multiple and interrelated drivers, with heterogeneous geographical and social impacts (Wenlock \& Buss 1977; Sonesson et al. 2005; Barr 2007; Koivupuro et al. 2012; Canali et al. 2014; Parizeau et al. 2015; Stancu et al. 2016; Setti et al. 2016). Hence, the identification and the design of effective policy interventions requires the comprehension of this complexity using a systems approach (Godfray et al. 2010).

The current approaches for identifying the drivers of food waste to design targeted policy interventions generally rely on frequentist statistics (i.e. null hypothesis testing) (e.g. Quested \& Luzecka 2014; Secondi et al. 2015). However, null hypothesis testing does not provide the probability of the null hypothesis or of its alternative; hence, its usefulness to underpin decision making is limited (Claxton 1997; Kileen 2005). In addition, the utility or "value" of a decision or intervention cannot be estimated or identified using null hypothesis testing (Claxton 1997). Assessments of food waste drivers using a regression framework often test multiple explanatory variables (Secondi et al. 2015, Stancu et al. 2016; Visschers et al. 2016). However, with an increased number of variables, the probability of Type I errors (i.e. false positives) increases. This, in combination with the problem of selective reporting and "researcher degrees of freedom" (i.e., the incomplete publication of the outcomes measured, or of the analyses performed; Simons et al. 2011; Reid et al. 2015; see Figure 5), which affects all scientific fields, implies that the actual drivers of household food waste cannot be reliably identified.

This represents a challenge for policy makers who may wish to use scientific papers as evidence to underpin robust policy decisions. Decision-analytic approaches may offer greater assistance 
to policy makers in situations where potential interventions are beset by complexity (Stewart et al. 2014). The processes of making decisions in the face of complexity and uncertainty have long been of academic interest; Bernoulli (in the 1700s) and Laplace (in the 1800s) addressed utility and probability in reference to decision making (Howard 2007). These theoretical applications of decision theory were robustly applied to the real world during the Second World War (which led to the development of the modern language associated with systems models) (Howard 2007). More recently, policy interventions in fields as diverse as public health (e.g. Nutt et al. 2010), sustainable energy (e.g. Wang et al. 2009) and natural resource management (e.g. Punt and Hilborn 1997) have been explored using decision analysis.

Differently from null-hypothesis testing, decision-theoretic approaches look at a problem in a systemic way, addressing the net changes in the outcome (i.e. the variable) of interest, rather than arbitrary levels of statistical significance (i.e. there is no test of statistical significance). Importantly, decision-theoretic approaches explicitly (and mathematically) incorporate uncertainty, which highly characterizes the data used to underpin the decisions on addressing food waste.

Secondi et al. (2015) used data from the Eurobarometer Flash survey (388) "Attitudes of Europeans to waste management and resource efficiency" (European Commission 2014) to identify the variables affecting food waste through a regression model (i.e. using frequentist statistics). Here, a similar but unique subset of the Eurobarometer dataset is used to identify the drivers of self-reported EU food waste, but it is analysed by means of a decision-theoretic approach. The reporting of the variable selection and statistical procedures in Secondi et al. (2015) were insufficient to replicate their study in full to allow a direct comparison of the two approaches. However, we demonstrate the potential for Type I error in a frequentist regression framework that does not account for model structural uncertainty. Our overarching goal is to highlight potential realms of interventions, and indicate which of them might help reduce food waste. As food waste is a complex issue, with many interrelated variables potentially affecting it, a systems model is used to assess it as a system in a probabilistic framework.

\section{Material and methods}

\subsection{Dataset}

The open-source Eurobarometer dataset is used. This dataset presents three main advantages: 1) it represents the largest survey on consumer attitudes to food waste in terms of sample size 
and geographical extent; 2) it registers the attitudes to food waste within the whole EU, thus capturing inter-country heterogeneity; 3) it represents a valid informative basis to support policy interventions under subsidiary schemes.

Eurobarometer Flash surveys were carried out through ad hoc thematic telephone interviews run at the request of the European Commission. The interviews used to build the dataset occurred in December 2013. Overall, 26,595 households were asked 20 questions on their attitudes and behaviours in relation to household food waste. Respondents were asked to estimate the amount of food purchased that goes to waste (see Table 1 for the categories). Additionally, demographic variables such as age, gender, nationality, age at which full-time education stopped, current occupation, location (urban, rural, etc.), phone ownership, and household composition (members aged 15 or over) were registered (for full details of the survey, see http://ec.europa.eu/public_opinion/flash/fl_388_en.pdf accessed November 11, 2016).

An important caveat throughout the discussion that follows concerns the subjective nature of the food waste measure considered. Although diary studies, and waste sorting or weighting analysis could also be used to quantify household food waste, questionnaires are the most common method due to their lower cost in terms of time and resources, even if their reliability is questionable (Van Herpen et al. 2016; Høj 2012; Ventour 2008). Indeed, when asked to quantify their own food waste, consumers tend to rely on judgment heuristics, such as availability (i.e. using the first piece of information coming to their mind, e.g. the last time they threw away food), and to be affected by systematic biases such as positive illusion, or social desirability, that lead to underestimation (Giordano 2016). Furthermore, when asked a percentage, like in the Eurobarometer survey, consumers need to make a double computation, which is subject to a frequency bias (Giordano 2016). These shortcomings may also be due to the fact that the Eurobarometer survey was carried out before the best practices to measure household food waste were systematically identified in Europe (Van Herpen et al. 2016). However, to date, it remains the only (and the largest) study at EU level that policy makers can use to design interventions against food waste.

\subsection{Systems model}

Fourteen variables were selected for the systems analysis (see Table 1), excluding those that did not potentially relate to household food waste or household socio-economic status (among 
123 others, the questions on whether the respondent thinks that an efficient resource use is related to employment opportunities and economic growth at country level were also excluded).

126 To detect the drivers of self-reported food waste, thus developing a candidate network of food 127 waste in the EU, a machine-learnt Bayesian Network (BN) was developed. BNs are graphical 128 representations of a network of variables (whereby related variables are joined by an arc, or arrow), and of a set of conditional probabilities (where the state of a variable is conditional on the states of $n$ others) (Bøttcher \& Dethlefsen, 2003). BNs can incorporate empirical data along with expert opinions. Full Bayesian hierarchical models allow more complete propagation of uncertainty than BNs, but BNs are less computationally complex and are, thus, much more transparent to stakeholders (Spiegelhalter et al., 2004; Bujkiewiez et al. 2011). Uncertainty in BNs is handled through sensitivity analysis.

To develop the $\mathrm{BN}$, the hill-climbing algorithm was used (this algorithm is included in the "bnlearn" package of the statistical software R; Scutari \& Denis 2014). This is an iterative algorithm which provides an arbitrary solution of a complex problem, then tries to find a better solution in terms of score (e.g., the Bayesian Information Criterion) by changing a single element of the initial solution; if the score improves, the process is repeated starting with the new solution, and so on.

\subsection{Sensitivity analysis \& scenario setting}

144 Following the standard BN methodology, a one-way sensitivity analysis and scenario setting was used to assess and interrogate the BN (Pitchforth \& Mengersen 2013). First, the state of one node (i.e. variable) at a time was changed, and the resulting probability of the food waste node (i.e. the level of self-assessed food waste) was recorded. The next section of the paper focuses on the self-reported food waste levels of " $5 \%$ or less" and " $50 \%$ or more", since these are likely to be the most relevant to policy makers. The focus on the level " $50 \%$ or more" allows the identification of the socio-economic and demographic characteristics of households with highest self-reported waste to be targeted by means of policies. The focus on the households who report " $5 \%$ or less" allows the appreciation of the differences between the least and the most (self-reported) wasters. Thus, the food waste node was set either at "5\% or less" or at " $50 \%$ or more", and the probabilities of each state in all the other nodes (i.e. the probabilities that the household presents certain characteristics given one of these two levels of self-assessed food waste, respectively) were recorded. Finally, a two-way sensitivity analysis 
157 was carried out, changing the state of two nodes at each step, and recording the resulting state of the food waste node.

\subsection{Type I errors in regression models}

161 Secondi et al. (2015) do not provide sufficient information to fully replicate their full model 162 structure. For example, there is no indication of how they addressed missing data in the Number

163 of Ecolabel licenses, in the Eurobarometer data, and how they partitioned Question 7 ("It would 164 convince me to separate (at least some) more of my waste"), a question with three more categories than those reported by them.

Secondi et al. (2015) use a binomial model ( 0 where the percentage of food wasted is greater than $5 \%$ of the food purchased; 1 if this percentage is $5 \%$ or less) with two levels (individual and country level variables). They do not account for model structural uncertainty in their assessment. In order to demonstrate the probability of Type I errors, we used their published list of variables (Table 4 in Secondi et al. 2015) to build a candidate set of binomial general linear models (GLMs). We only used the individual level variables, to reduce model complexity and processing time. We used the Akaike Information Criterion corrected for small sample size (AICc) to determine a set of the top 100 plausible (most parsimonious) model structures (Burnham \& Anderson 2002). For each of these models, we extracted the p-value and plotted the distribution to illustrate the potential for Type I errors. GLMs, and model selection were carried out using the "glmulti" package (Calcagno 2015) in the R programme.

\section{Results}

\subsection{Systems model}

181 The structure of the systems model is reported in Figure 1. The country and the age of the respondent, as well as a self-reported belief that the family wastes too much lead to the largest variation (i.e. there is a large amount of uncertainty associated with these nodes) in the food waste node (Figure 2). The level of education has also a strong impact on self-reported food waste.

The age of the respondent causes the largest variation in the probability of wasting " $50 \%$ or more", followed by country of residence, while for the probability of wasting " $5 \%$ or less" the positions are reversed. The third largest variation is due to the level of education, followed by the belief of wasting too much, the size of the household, and the occupational status. Gender 
191 has a limited impact, and only on the probability of wasting " $5 \%$ or less" of one's purchased food. It is worth noting that much more than half of the respondents declared to waste " $5 \%$ or less" of their food, while less than $1 \%$ declared wasting " $50 \%$ or more" of their food.

194 There are considerable country-level differences in self-reported food waste (Figure 3). The majority of respondents in all countries reported " $5 \%$ or less" of the food purchased going to waste; in Estonia and Lithuania, over 20\% reported to waste "none" of it. The shares of respondents reporting higher levels of waste, as well as those reporting "none" show much more variability among countries, compared to the answer " $5 \%$ or less". Portugal, Greece,

199 Bulgaria, Cyprus, Latvia and Romania have the highest percentage of respondents reporting that they discard " $50 \%$ or more" of their food. Estonia, Lithuania, Malta and, again Romania and Latvia have the highest percentage of respondents reporting that they waste "none" of their food. Interestingly, all countries where over $10 \%$ of the respondents declared to waste "none" of their food (apart from Malta) are post-communist countries that joined the EU in 2004 or later.

Figure 4 shows the state of the most influential nodes given a specific state of the food waste node (either " $5 \%$ or less", or " $50 \%$ or more"). The age of the respondent has a strong impact on self-assessed food waste: as this variable increases, the probability of wasting " $5 \%$ or less" of one's purchased food increases steadily, while the probability of wasting " $50 \%$ or more" decreases, although less steadily (Figure 4). A similar pattern can be detected through two-way sensitivity analysis, by limiting food waste to " $50 \%$ or more", and the countries to Greece,

212 Latvia and Cyprus. These three countries were hit particularly hard by the financial crisis and

213 the austerity measures that followed.

215 The level of education does not appear to have a strong impact on self-reported food waste; 216 however, compared to the others, the respondents who were "still studying" show a higher 217 probability of reporting " $50 \%$ or more", and a lower probability of reporting " $5 \%$ or less" food 218 waste. As for the household size, it is an important variable when looking at the probability of 219 wasting " $50 \%$ or more": the families of three or more members show a greater probability of reporting that they waste a high share of food. Large amounts of self-declared food waste are also more likely to be observed in neighbourhoods with "a lot" or "quite a lot" of litter, and among employees and self-employees. In contrast, households of one person, respondents living in cleaner neighbourhoods, and unemployed respondents are more likely to waste " $5 \%$ 
224 or less" of their food compared to other groups. Finally, the amount of self-declared food waste is strongly positively associated with the belief that the family is wasting too much, confirming the role of one's perception in driving self-reported food waste levels.

\subsection{Type I errors in regression models}

The binomial models with individual level variables and no interaction terms had a potential of $134,217,728$ different model structures. We took the top 100 models, and plotted the distribution of the p-values for each variable (Supplementary Figure S1). Broadly, the results of this analysis of the binomial regression models agree with the systems model. For example, the age of the respondents and the response to question 4(2) ("I think my household is generating too much waste") were consistently statistically significant $(\mathrm{p}<0.05)$. There was no support for differences between rural and urban locations (i.e. we assume that statistically significant findings relating to these variables would have a high probability of being Type I errors).

\section{Discussion}

240 Using a systems approach to analyse the phenomenon of household food waste in the EU, we have shown that the country and the age of the respondent, as well as the fact of being a student, and a belief that the family wastes too much are key drivers of self-assessed food waste. It is important to reiterate that, being self-reported, the level of waste can be potentially biased (Ventour 2008). This remains an important - and method-independent - caveat throughout the discussion that follows. However, the fact that the belief of wasting too much is related to the probability of reporting a level of food waste of " $50 \%$ or more" suggests that respondents are aware, to an extent, of their waste levels.

Our findings deviate in several key aspects from those of Secondi et al. (2015), who adopt a structured binomial regression approach to assess another subset of variables from the same dataset. These authors identified a difference in the food waste behaviour between people living in towns or cities, and those living in rural areas, with the former wasting more food. In contrast, the BN shows that there is very little effect of the place of residence on the level of self-reported food waste. Furthermore, Secondi et al. (2015) ascertain as statistically significant the gender of the respondent, suggesting that women waste less food than men. The BN finds very limited support for this. The reasons for these differences are related, among others, to the fact that decision analysis methods do not rely on arbitrary measures (i.e. levels) of statistical 
significance to assess the effects of variables, being thus robust to false-positives (Type I errors). Additionally, using a multinomial approach further avoids over-estimating the differences in these variables.

Secondi et al. (2015) show that education is significantly positively related with food waste generation: the more the number of years spent in education, the larger the amount of selfdeclared food waste. They relate this pattern either to the higher income of more educated people, that allows them to waste more, or to the inability of less educated people to correctly estimate their food waste. The BN does not support this finding; however, it shows that students are more likely to waste " $50 \%$ or more", and less likely to waste " $5 \%$ or less" of the food they purchase, compared to other groups. This may be related to the financial pressure that may affect students regardless of their country, causing them to purchase lower quality or perishable food, or to their irregular food provisioning practices and eating behaviours, that prevent consistent planning.

Age was identified as an important determinant of food waste, in line with Secondi et al. (2015) and many others (e.g. Wassermann \& Schneider 2005; IGD 2007; Glanz 2008; Koivupuro et al. 2012; Quested \& Luzecka 2014; Parizeau et al. 2015). We confirm this results with our system approach. The older the respondent, the smaller the probability of reporting high levels of food waste. Younger people should, thus, be one of the main targets of policy interventions to reduce food waste.

Household size is considered a significant driver of food waste in many studies (Wenlock \& Buss 1977; Wassermann \& Schneider 2005; IGD 2007; Barr 2007; Glanz 2008; Koivupuro et al 2012; Quested \& Luzecka 2014; Parizeau et al. 2015). The BN analysis confirms this finding: larger households have a greater probability of reporting higher levels of food waste, although it should be pointed out that the Eurobarometer survey measures household size differently from other studies (i.e., only family members aged 15 or more years are considered).

Secondi et al. (2015) identify richer EU countries as potential targets of policy interventions to reduce food waste, because they find that their citizens tend to waste more (i.e., they have a higher probability of declaring to waste more than $5 \%$ of their food). Nevertheless, the results of the BN suggest that respondents from poorer counties (i.e. Portugal, Greece, Bulgaria, Cyprus, Latvia and Romania) have a higher probability of declaring to waste " $50 \%$ or more" 
292 of their food, and should thus be a focus of related policy intervention and awareness 293 campaigns. There are several competing explanations for this apparent contradiction with the 294 findings of Secondi et al. (2015), the first is analytical and the others sociological. Secondi et 295 al. (2015) use a binomial model with the data split from the original 7 categories of food waste 296 down to only two levels (less than $5 \%$ or greater than $5 \%$ ), this split means that there may be 297 still more people wasting 5\% to 50\% in richer countries, while in poorer countries there are 298 relatively more people wasting "none" or "50\% or more". The fact that some EU countries, 299 most of which from Eastern Europe (Estonia, Lithuania, Malta, Romania, Latvia, Hungary, 300 Slovakia, Poland and Bulgaria), have also a higher share of respondents reporting no food 301 waste at all suggests that there may be different understandings of what constitutes food waste 302 in different countries. For example, food leftovers used to feed animals tend not to be considered waste in some EU Member States (Parfitt et al. 2010). Indeed, respondents were not provided a definition of food waste during the survey (European Commission 2014). Furthermore, in Bulgaria, Hungary, Latvia and Romania (the four poorest EU countries by GDP (PPP) per capita; IMF 2013) the share of respondents declaring to waste "none" of their food and the share of those declaring to waste " $50 \%$ or more" are both above the average. The poor countries whose respondents have a higher probability of declaring to waste " $50 \%$ or more" of their food are all characterised by a low level of post-materialist self-expression values and, thus, by a low environmental awareness (Inglehart \& Baker 2000). Hence, compared to rich countries, the respondents who have enough resources to waste food are less likely to be affected by social desirability bias, and more likely to declare that they waste much food. On the other hand, there should be a larger share of the population acting virtuously out of necessity. This suggests that poverty and, especially, high levels of income inequality, may generate a larger polarization in declared food waste behaviours.

317 Within each country, different age groups show different food waste behaviour. For example, 318 in Portugal, middle-age consumers (aged 35 to 44 ) are the most likely to report " $50 \%$ or more" 319 food waste. Instead, in Latvia, Greece and Cyprus, the most likely to produce such high level 320 of waste are the respondents aged 15 to 34, and in Bulgaria, those aged 25 to 44. Overall, elderly households tend to waste less.

323 Country-level policies to address food waste have been developing at different rates across the 324 EU. When the Eurobarometer survey was carried out in 2013, food waste was already the object 325 of national communication campaigns and of targeted national policies in some, mostly 
326 industrialized, EU member States, namely Austria, Denmark, France, Germany, Italy, the 327 Netherlands, and the United Kingdom (BCFN 2012; Monier et al. 2011; Secondi et al. 2015). 328 However, in most of the countries that had joined the EU either in 2004 (Estonia, Latvia, 329 Lithuania, Cyprus, and Malta) or in 2007 (Romania and Bulgaria), food waste was neither the 330 objective of targeted communication campaigns, nor considered by national policies. In 331 addition, no uniform definition of food waste was available at EU level in 2013 (Östergren et 332 al. 2014). Different countries had different definitions, while quantification was rather weak, 333 and limited mainly to the estimates by Monier et al. (2011) and FAO (2011). This lack of 334 knowledge (especially in some countries) might have influenced the outcome of the survey even more than cultural differences

(See

336 http://ec.europa.eu/environment/archives/eussd/pdf/bio foodwaste report.pdf; accessed

337 October 18, 2016).

An important caveat in our comparisons to Secondi et al. (2015) is that we were unable to replicate their model because not all information we needed to do so was available in the publication (perhaps due to space constraints). This is a common problem hindering the replication of scientific analyses, and does not (routinely, at least) indicate nefarious practices (Gellman \& Loken 2013). Researcher degrees of freedom (Simmons et al. 2011), and the (often hidden) decisions that researchers take in data collection and analysis increase the probability of Type I errors. In order to carry out an analysis, researchers must make a myriad of decisions on which variables to measure, how much data to collect, how to dichotomise or transform variables, etc. Figure 5 attempts to estimate the cumulative number of different decisions that one would have to take in order to analyse the Eurobarometer data in relation to food waste. Decisions made at each stage could fundamentally change the nature of the inference one makes from the data.

\section{Conclusions and policy recommendations}

353 The results showed the effectiveness of a systemic approach for detecting hidden interactions among variables. This is particularly true when a complex socio-economic issue like food waste is concerned, and if the data refer to a heterogeneous geographical area like the EU. Rather than adopting arbitrary levels of statistical significance, or imposing an a priori model to the data, machine-learnt BNs detect the structure of the relationships among variables from the data themselves. This allowed us to uncover new results and to highlight a number of differences compared to Secondi et al. (2015), despite using a similar dataset. While they find 
360 the place of residence (urban, semi-urban, rural), the level of education, and the gender of the respondent to be three important determinants of the amount of self-declared food waste, the BN highlighted the role of household size, and of the status of being a student. The age and the country of the respondent were identified as being relevant drivers of food waste by both methodologies. However, while Secondi et al. (2015) argue that richer EU Member States show higher level of waste, the BN suggests that respondents from poorer countries are more likely to waste " $50 \%$ or more" of their food.

These findings call for a comprehensive EU strategy, neglected by previous studies on food waste. Due to the country-level heterogeneity identified, such strategy should include both EUand national-level measures, making an effective use of subsidiarity. Previous studies have grouped the policies addressing food waste into suasive, regulatory, market-based, and public service provision (Aramyan et al. 2016). These policy typologies should be integrated into a mix tailored to individual countries, or groups of countries. Moreover, within these countries, the socio-demographic groups identified by our BN as more incline to waste food should be addressed by means of targeted policy interventions.

In low-income countries where knowledge of the food waste problem is still limited, formal educational programmes targeting school children and university students, as well as national campaigns targeting middle-aged citizens could be used to raise awareness, while stricter ("command-and-control"; Vittuari et al. 2016) regulations on food safety and management by retail supermarkets could help increase the life of perishable products and discourage overbuying by those wasting "more than $50 \%$ " of their food while, at the same time, helping consumers to reify the existence of the food waste problem. At the same time, income support policies could lead the poorest to buy better quality food, less likely to be wasted. These measures should be implemented in synergy with local administrations (i.e. adopting vertical subsidiarity). In higher-income countries, instead, the awareness of environmental problems is more widespread, and local institutions have more resources and a better organisational capability. Here, multi-stakeholder governance of food supply chains (e.g. by involving consumer organizations within the management boards of large-scale retailers, thus implementing horizontal subsidiarity) could be implemented drawing on the experience of the EU Platform on Food Losses and Food Waste (Ibid). Furthermore, market-based instruments could be effectively adopted to reduce household food waste. These include, in particular, 
393

394

395

396

397

negative price-based incentives, like the "pay-as-you-throw" principle applied to organic waste by means of weight and frequency-based schemes (Aramyan et al. 2016).

BNs allow the identification of dependencies among variables, but not their direction and their mechanisms (i.e. causality). Understanding why age and country-level differences occur may be of paramount importance for designing better policy interventions. Nevertheless, the probabilistic understanding of the drivers of food waste we have developed here allows further targeted action and research. Determining the mechanisms behind these drivers could be a key area for this future research. In particular, the reasons why students waste a large amount of food, and especially the complex relationship between food waste and (household or local) income levels may need to be understood. "Mixed-method" approaches might prove useful in combining the strengths of quantitative and qualitative research to better interpret the context of the results (Phyel \& Hong 2014).

Finally, there are some measures that policy-makers can use to assess the quality of evidence presented in scientific papers regardless of the statistical discipline they follow. For example, more reliable evidence might be found in papers that;

- interpret the results in terms of the size of the effect (with a clear indication of the range of possible outcomes, e.g. confidence limits, standard deviations, probabilities, etc.) rather than in purely statistical terms (e.g. "significantly different", or " $p<0.05$ ", etc.);

- use some form of model selection to identify the most suitable structure of a model rather than rely on a single structure alone;

- carefully select variables with a rationale for inclusion;

- have a pre-published protocol usable to identify the variables, that will be tested and processed to reduce the biases undertaken by the researcher - this is a popular approach in meta-analysis and systematic review, but can be applied more widely;

- provide access to data and analysis work flows to allow replication of the study findings (all data and workflows for this analysis are available at https://osf.io/ye9dp/?view_only=4469bc2368a942a59f7ad239427cc8fb).

Policy-makers may wish to make use of existing, or commission new, systematic reviews or meta-analysis to determine the strength of evidence and direction of effects. Systems models 
The use of systems models to identify food waste drivers

425 (e.g. BNs) can then be used to place the results from systematic reviews and meta-analysis into 426 a wider policy-relevant context.

427

\section{Acknowledgements}

429 This work was carried out under the H2020 project REFRESH - Resource Efficient Food and 430 dRink for the Entire Supply cHain. REFRESH is funded by the Horizon 2020 Framework 431 Programme of the European Union under Grant Agreement no. 641933. The views reflected in 432 this article represent the professional views of the authors and do not necessarily reflect the 433 views of the European Commission or other REFRESH project partners. We thank Toine 434 Timmermans, Hilke Bos-Brouwers, Hans van Trijp, Erica van Herpen, Graham Moates and 435 Keith Waldron for comments on an earlier draft of this paper. 


\section{References}

Aramyan, L., Valeeva, N., Vittuari, M., Gaiani, S., Politano, A., Gheoldus, M., Mahon, P., Scherhaufer, S., Paschali, D., Cseh, B., Ujhelyi, K., Hanssen, O.J. 2016. Market-based instruments and other socio-economic incentives enhancing food waste prevention and reduction. FUSIONS EU Project Report.

Calcagno, V. 2013. glmulti: Model selection and multimodel inference made easy. R package version 1.0.7. https://CRAN.R-project.org/package=glmulti

Barr, S. 2007. Factors influencing environmental attitudes and behaviours. A U.K. case study of household waste management. Environ. \& Behav. 39 (4), 435-473.

BCFN, Barilla Centre for Food and Nutrition. 2012. Food Waste: Causes, Impacts and Proposals. Turin: Codice Edizioni.

Burnham, K.P., Anderson, D.R. 2002. Model Selection and Multimodel Inference: A Practical Information-Theoretic Approach, Springer

Canali, M., Östergren, K., Amani, P., Aramyan, L., Sijtsema, S., Moates, G., Waldron, K., O'Connor, C. 2014. Drivers of current food waste generation, threats of future increase and opportunities for reduction. FUSIONS EU Project Report.

Claxton, K. 1997. The irrelevance of inference: A decision-making approach to the stochastic evaluation of heath care technologies. CHE Technical Paper Series 8, York, UK.

European Commission. 2014. Attitudes of Europeans towards waste management and resource efficiency. http://ec.europa.eu/public_opinion/flash/fl_388_en.pdf

European Commission. 2015. Proposal for a DIRECTIVE OF THE EUROPEAN PARLIAMENT AND OF THE COUNCIL amending Directive 2008/98/EC on waste $\mathrm{COM} / 2015 / 0595$ final $\quad$ - 2015/0275 (COD) http://eur-lex.europa.eu/legalcontent/EN/TXT/?uri=CELEX:52015PC0595

FAO. 2013. Food wastage footprint impacts on natural resources. Rome http://www.fao.org/docrep/018/i3347e/i3347e.pdf

FAO. 2011. Global food losses and food waste - Extent, causes and prevention. Rome

Gelman, A., Loken, E. 2013. The garden of forking paths: Why multiple comparisons can be a problem even where there is no "fishing expedition" or "p-hacking" and the research 
The use of systems models to identify food waste drivers

466

hypothesis

was

posited

ahead

of

time. www.stat.columbia.edu/ gelman/research/unpublished/p_hacking.pdf

Giordano, C. 2016. Assessing Household Food Waste in Italy: A Methodology for Detecting Drivers and Quantities. PhD Thesis, Dottorato di ricerca in Scienze e Tecnologie Agrarie, Ambientali e Alimentari, Alma Mater Studiorum Università di Bologna, Bologna, Italy.

Glanz, R. 2008. Causes of food waste generation in households - an empirical analysis. MSc Thesis, University of Natural Resources and Applied Life Sciences, Vienna and Cranfield University Institute of Waste Management and School of Applied Sciences.

Godfray, H. C. J., Beddington, J. R., Crute, I. R. Lawrence Haddad, Lawrence, D., Muir, J.F., Pretty, J., Robinson, S., Thomas, S. M., Toulmin, C. 2010. Food security: The challenge of feeding 9 billion people. Sci. 327, 812-818.

Høj, S.B. 2012. Metrics and measurement methods for the monitoring and evaluation of household food waste prevention interventions. Ehrenberg-Bass Inst. Mark. Sci. University of South Australia.

Howard, R. A. 2007. The Foundations of Decision Analysis Revisited. In W. Edwards, R. F. Miles Jr., \& D. von Winterfeldt (Eds.), Advances in Decision Analysis: From Foundations to Applications. New York, Cambridge University Press.

http://dx.doi.org/10.1017/CBO9780511611308.004

IGD. 2007. Beyond Packaging: Food Waste in the Home. Institute of Grocery Distribution, Watford, UK.

IMF. 2013. World Economic and Financial Surveys. World Economic Outlook Database. http://www.imf.org/external/pubs/ft/weo/2013/02/weodata/index.aspx

Inglehart, R., Baker, W.E. 2000. Modernization, Cultural Change, and the Persistence of Traditional Values. Am. Sociol. Rev. 65 (1), 19-51.

Kileen, P. 2005. Beyond statistical inference: A decision theory for science. In Psychonomic Bull. \& Rev. 13 (4), 549-562.

Koivupuro, H-K., Hartikainen, H., Silvennoinen, K., Katajajuuri, J-M., Heikintalo, N., Reinkainen, A., Jalkanen, L. 2012. Influence of socio-demographical, behavioural and attitudinal factors on the amount of avoidable food waste generated in Finnish households. Int. J. Consumer Behav. 1080, 183-191. 
496

497

498

499

500

501

502

503

504

505

506

507

508

509

510

511

512

513

514

515

516

517

518

519

520

521

522

523

524

525

526

Monier, V., Shailendra, M., Escalon, V., O’Connor, C., Gibon, T., Anderson, G., Hortense, M., Reisinger, H. 2011. Preparatory Study on Food Waste across EU 27. European Commission (DG ENV) Directorate C-Industry. 2010. Final Report.

Nutt, D.J., King, L.A, Phillips, L.D. 2010. Drug harms in the UK: a multicriteria decision analysis. Lancet, 376. 1558-65.

Östergren, K., Gustavsson, J., Bos-Brouwers, H., Timmermans, T., Hansen, O.-J., Møller, H., Anderson, G., O’Connor, C., Soethoudt, H., Quested, T., Politano, A., Bellettato, C., Canali, M., Falasconi, L., Gaiani, S., Vittuari, M., Schneider, F., Moates, G., Waldron, K., Redling, B. 2014. FUSIONS Definitional Framework for Food Waste. Göteborg: SIK - The Swedish Institute for Food and Biotechnology.

Parfitt, J., Barthel, M., Macnaughton, S. 2010. Food waste within food supply chains: quantification and potential for change to 2050. Philosophical Trans. of the R. Soc. B. 365, 3065-3081.

Parizeau, K., von Massow, M., Martin, R. 2015. Household-level dynamics of food waste production and related beliefs, attitudes, and behaviours in Guelph, Ontario. In Waste Man. $35,207-217$.

Phyel, P. Hong, Q.N. 2014. Combining the Power of Stories and the Power of Numbers: Mixed Methods Research and Mixed Studies Reviews. Annu. Rev. Public Health. 35, 29-45.

Pitchforth, J., Mengersen, K. 2013. A proposed validation framework for expert elicited Bayesian Networks. Expert Systems with Applications. 40 (1), 162-167.

Punt, A.E., Hilborn. R. 1997. Fisheries stock assessment and decision analysis: The Bayesian approach. Rev Fish Biol Fisher. 7 (1), 35-63.

Quested, T., Luzecka, P. 2014. Household food and drink waste: A people focused report. WRAP, Banbury, UK.

Reid, E.K., Tejani, A.M., Huan, L.N., Egan, G., O’Sullivan, C., Mayhew, A.D., Kabir, M. 2015. Managing the incidence of selective reporting bias: a survey of Cochrane review groups. Systematic Reviews. 4, (85).

Secondi, L., Principato, L., Laureti, T. 2015. Household food waste behaviour in EU-27 countries: A multilevel analysis. In Food Policy. 56, 25-40.

Setti, M., Falasconi, L., Cusano, L., Segrè, A., Vittuari, M. 2016. Italian consumers' income and food waste behavior. British Food J. 118 (7), 1-18. 
Simmons, J.P., Nelson, L.D. \& Simonsohn, U. 2011 False-positive psychology: undisclosed Flexibility in data collection and analysis allows presenting anything as significant. Psychological Science, 22: $1359-1366$

Sonesson, U., Anteson, F., Davis, J., Sjödén, P-O. 2005. Home transport and wastage: Environmentally relevant household activities in the life cycle of food. Ambio. 34 (4/5), $371-375$.

Stancu, V., Haugaard, P., Lähteenmäkiet, L. 2016. Determinants of consumer food waste behaviour: Two routes to food waste. Appetite. 96, 7-17.

Stenmarck, Å, Jensen, C., Quested, T., Moates, G. 2016. Estimates of European food waste levels. FUSIONS EU Project Report.

Stewart, G.G., Mengersen, K., Meader, N. 2014. Potential uses of Bayesian networks as tools for synthesis of systematic reviews of complex interventions. Res Synth Methods. 5, 1-12.

UNEP. 2016. Food Loss and Waste Accounting and Reporting Standard. UNEP, Copenhagen//Washington.

Van Herpen, E., van der Lans, I., Nijenhuis-de Vries, M., Holthuysen, N., Kremer, S. 2016. Best practice assessment consumer level food waste. REFRESH EU Project Report.

Ventour, L. 2008. Food Waste Report - The Food We Waste. Waste \& Resources Action Programme (WRAP): Banbury, UK, 2008.

Visschers, V. H., Wickli, N., Siegrist, M. 2016. Sorting out food waste behaviour: A survey on the motivators and barriers of self-reported amounts of food waste in households. In J. Env. Psychol 45, 66-78.

Vittuari, M., Azzurro, P., Gaiani, S., Gheoldus, M., Burgos, S., Aramyan, L., Valeeva, N., Rogers, D., Östergren, K., Timmermans, T., Bos-Brouwers, H. 2016. Recommendations and guidelines for a common European food waste policy framework. FUSIONS EU Project Report.

Wang, J.J. Jing, Y.Y., Zhang, C-F., Zhao, J-H. 2009. Review on multi-criteria decision analysis aid in sustainable energy decision-making. Renew. Sustainable Energy Rev., 13, 2263-2278.

Wassermann, G., Schneider, F. 2005. Edibles in household waste. In Proceedings Sardinia 2005, Tenth International Waste Management and Landfill Symposium S. Margherita di Pula, Cagliari, Italy; 3-7 October 2005. 
557 Wenlock, R.W., Buss, D. H. 1977. Wastage of edible food in the home: a preliminary study. In $558 \quad$ J.Hum. Nutrition. 31 (6), 405-11.

559 Bøttcher, S.G., Dethlefsen, C. 2003. DEAL: A package for learning Bayesian networks 560 http://www.math.auc.dk/novo/deal

561 Bujkiewicz, S., Jones, H.E., Lai, M.C.W., Cooper, N.J., Hawkins, N., Squires, H., Abrams, 562 K.R., Spiegelhalter, D.J., Sutton, A.J. 2011. Development of a Transparent Interactive 563 Decision Interrogator to Facilitate the Decision-Making Process in Health Care. Value in $564 \quad$ Health.14, 768-776.

565 Spiegelhalter, D.J., Abrams, K.R., Myles, J.P. 2004. Bayesian Approaches to Clinical Trials 566 and Health-Care Evaluation.Wiley, England. 
Table 1. Variables included in the dataset used within this paper.

\begin{tabular}{|c|c|c|}
\hline Eurobarometer 388 question & Variable name & States \\
\hline \multirow{7}{*}{$\begin{array}{l}\text { Q9: Can you estimate what } \\
\text { percentage of food you buy } \\
\text { goes to waste? }\end{array}$} & \multirow[t]{7}{*}{ Food waste } & More than $50 \%$ \\
\hline & & 31 to $50 \%$ \\
\hline & & 16 to $30 \%$ \\
\hline & & 6 to $15 \%$ \\
\hline & & $5 \%$ or less \\
\hline & & None \\
\hline & & Did not answer \\
\hline \multirow{24}{*}{$\begin{array}{l}\text { D3a: What is your } \\
\text { nationality? Please tell me } \\
\text { the country(ies) that } \\
\text { applies(y). }\end{array}$} & \multirow[t]{24}{*}{ Country } & Austria \\
\hline & & Belgium \\
\hline & & Bulgaria \\
\hline & & Croatia \\
\hline & & Cyprus (Republic) \\
\hline & & Czech Republic \\
\hline & & Denmark \\
\hline & & Estonia \\
\hline & & Finland \\
\hline & & France \\
\hline & & Germany \\
\hline & & Greece \\
\hline & & Hungary \\
\hline & & Ireland \\
\hline & & Italy \\
\hline & & Latvia \\
\hline & & Lithuania \\
\hline & & Luxembourg \\
\hline & & Malta \\
\hline & & Poland \\
\hline & & Portugal \\
\hline & & Romania \\
\hline & & Slovakia \\
\hline & & Slovenia \\
\hline
\end{tabular}


Spain

Sweden

The Netherlands

United Kingdom

D2: Gender

Gender

Male

Female

Q3 Which of the following

Home waste

Yes

actions do you think would

No

make the biggest difference

in how efficiently we use

resources? Reducing waste

at home.

Q17: How much litter is

Litter

Quite a lot

there in the area where you

A lot

live (litter on the street, in

None

natural surroundings, etc.)?

Not much

Don't know

Q6 Do you sort the

Kitchen waste

Yes

following types of waste, at

No

least occasionally? Kitchen

waste.

D4: How old were you

Education

Still Studying

when you stopped full-time

Up to 15

education?

16-19

20 years and older

No full-time education

Don't know

Refusal

D5: As far as your current Employ

Employees

occupation is concerned,

Manual workers

would you say you are self-

Not working

employed, an employee, a

Refusal 
manual worker or would

you say that you are without

a professional activity?

D1.1 How old are you?

D18 - Have you got a

mobile phone?

D20 - Have you got a

landline phone?

Q4.3 For each of the

following statements, please

tell me whether you totally

agree, tend to agree, tend to

disagree or totally disagree.

You make efforts to reduce the amount of household waste that you generate.

Q4.2: For the following statement, please tell me whether you totally agree, tend to agree, tend to disagree or totally disagree:

"Your household is generating too much waste" D22: Could you tell me how many people aged 15 years or more live in your
Age

15 - 24 years

25 - 34 years

35 - 44 years

45 - 54 years

55 - 64 years

65 years and older

Refused to answer

Phone

Landline only

Mobile and landline

Mobile only

Reduce waste

Totally agree

Tend to agree

Tend to disagree

Totally disagree
Too much

Totally agree

Tend to agree

Tend to disagree

Totally disagree

Household 1 
The use of systems models to identify food waste drivers

\begin{tabular}{ll}
\hline household, yourself & Don't know \\
included? & Refused to answer \\
D13 Would you say you live Community & Large town \\
in a...? & Rural area or village \\
& Small or middle-sized town \\
& Don't know
\end{tabular}

570

571 


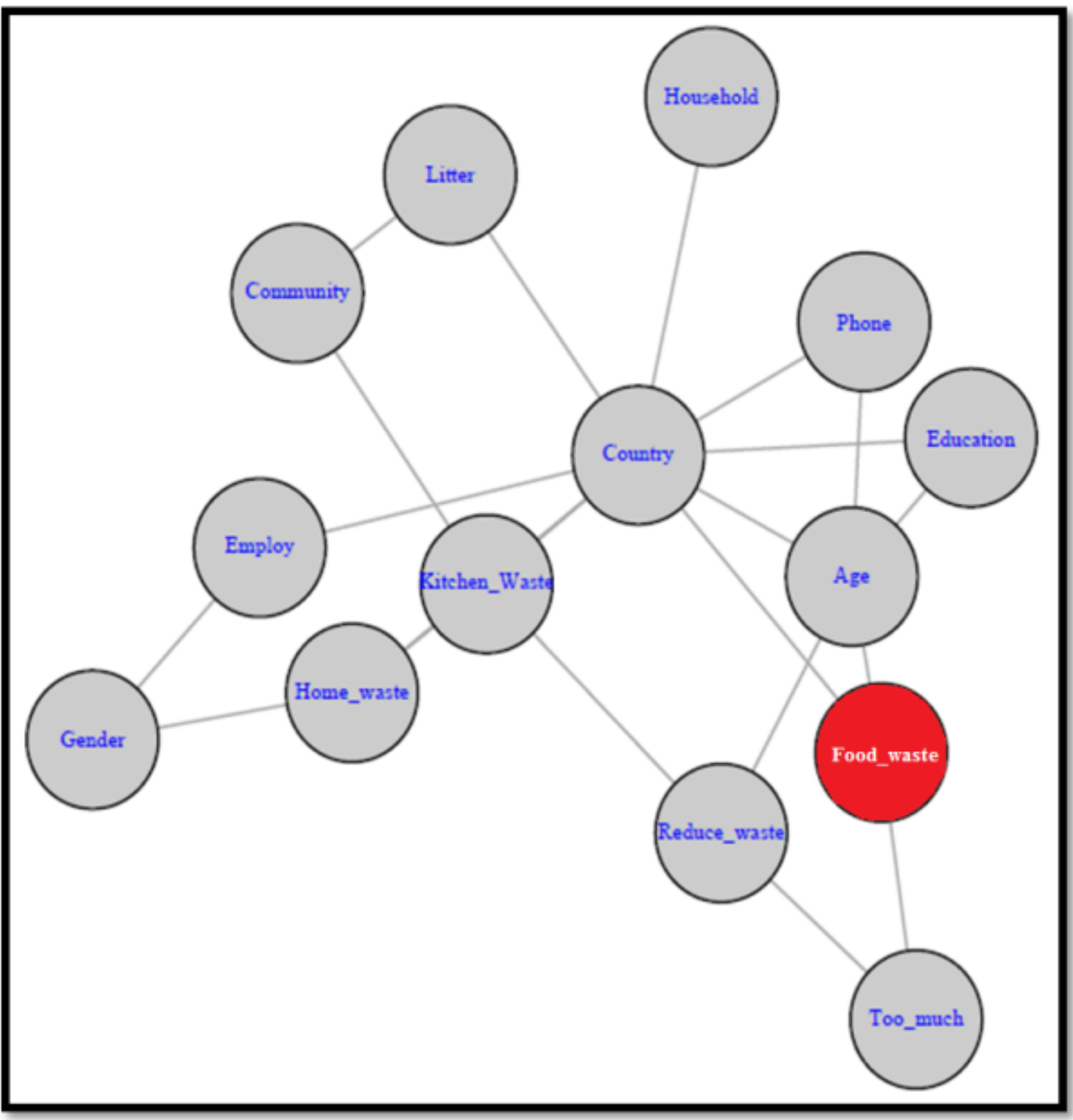

Figure 1. The machine-learnt structure of the Eurobarometer 388 dataset in relation to self-reported food waste (see Table 1 for a description of the variables). 


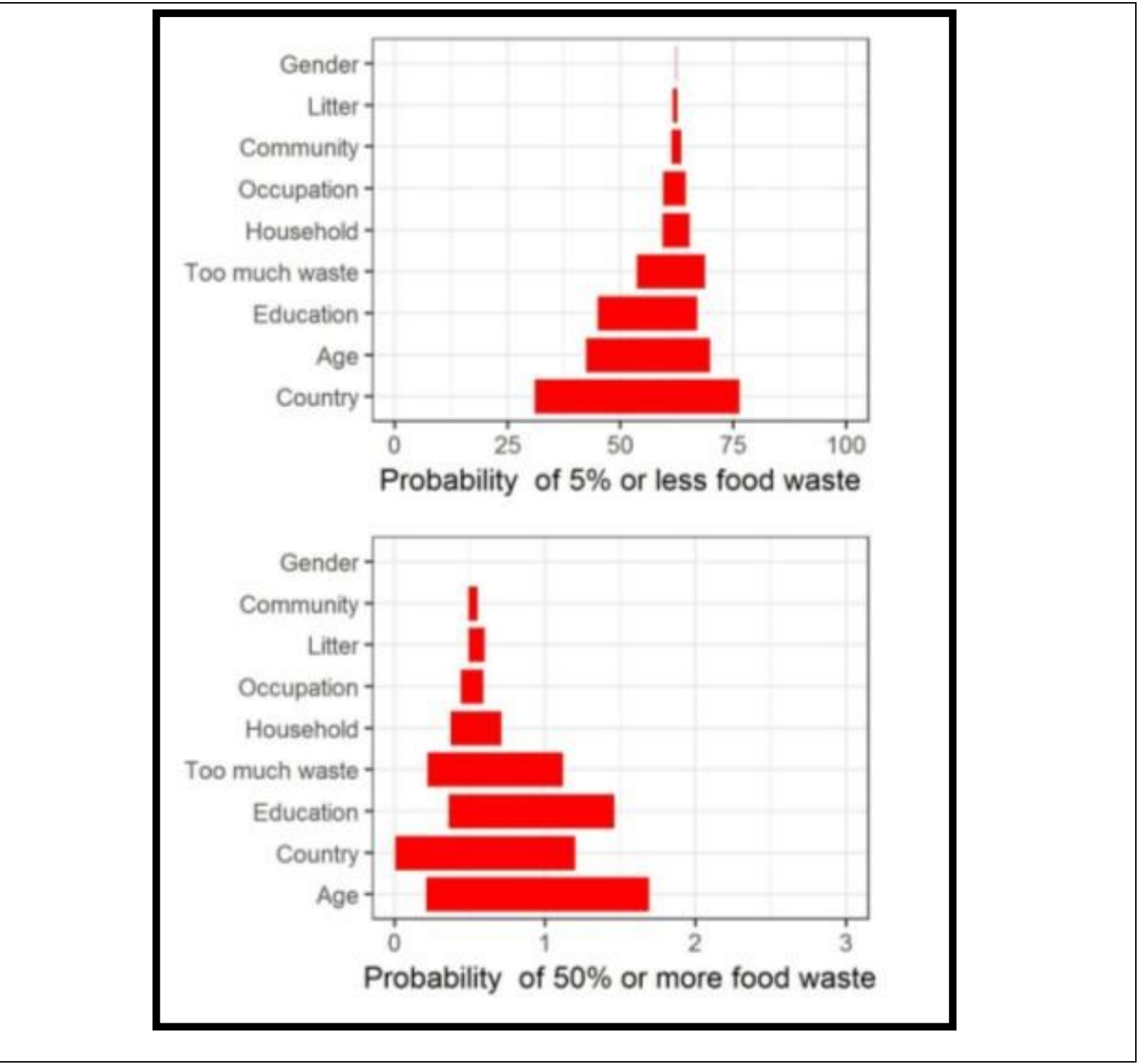

Figure 2. The sensitivity of the food waste node given the variation of the nine nodes that have the largest effect on it. The largest uncertainty occurs in the state of the "5\% or less" (upper graph) when we change the state of the Country node (i.e. there is a lot of variation between countries). For the state "50\% or more" (lower graph) the largest uncertainty occurs when we vary the Age node. 

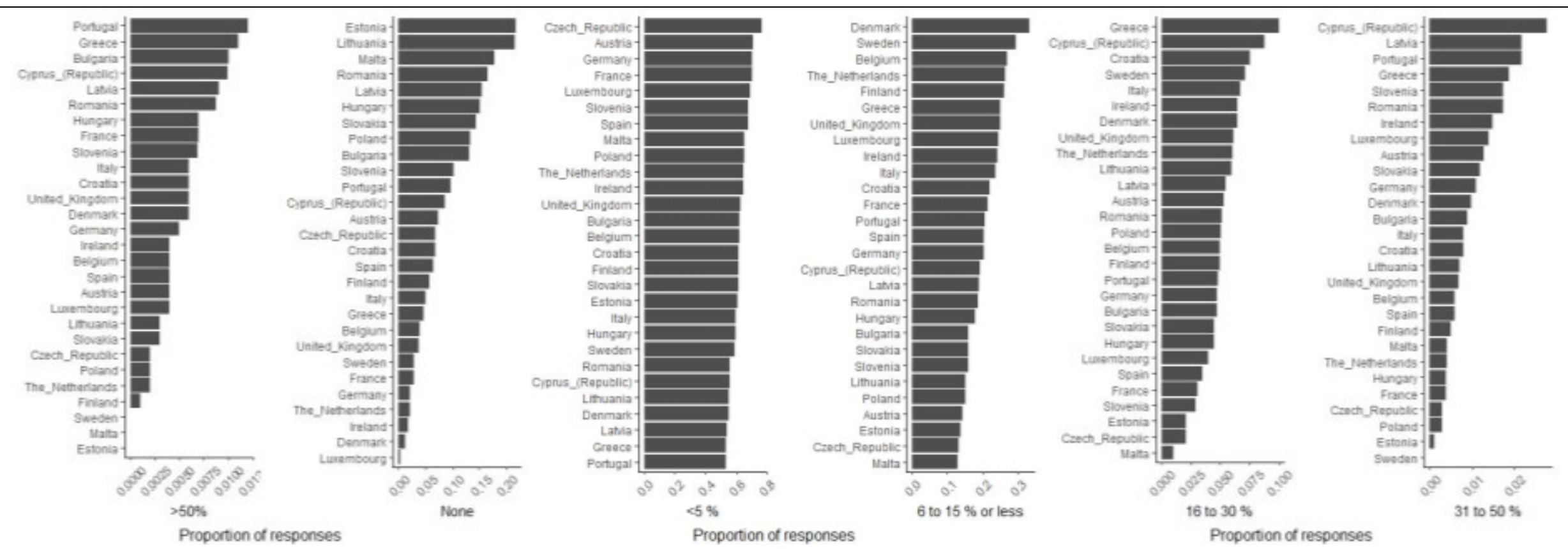

Figure 3. Percentage of respondents who selected each of the six states of the food waste node in each EU Member State. 


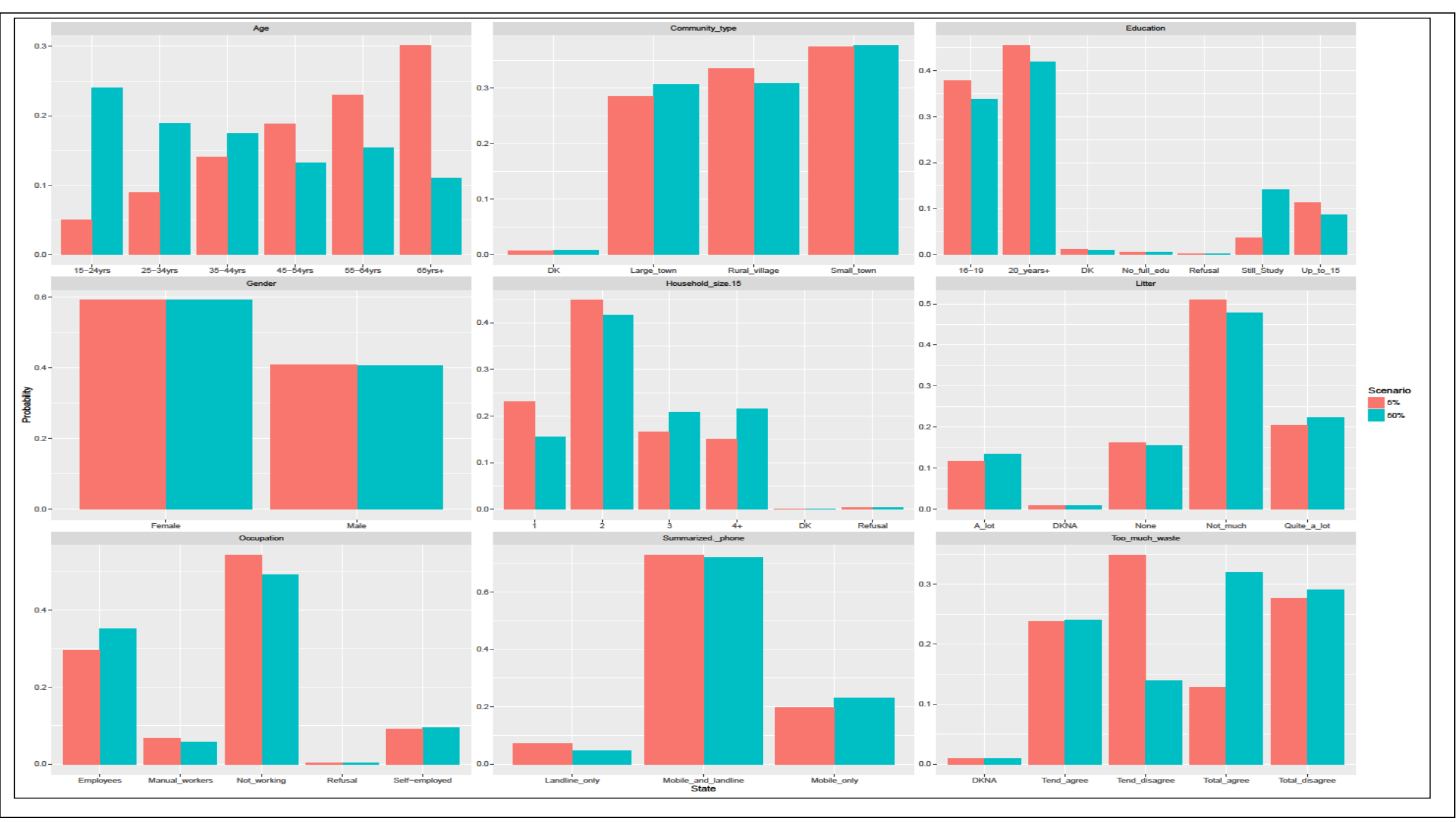

Figure 4. State of the nodes which show the largest effect on self-reported food waste (apart from country, but including phone ownership)

given the states " $5 \%$ or less" (red bars) and " $50 \%$ or more" (blue bar) of the food-waste node, respectively 
The use of systems models to identify food waste drivers

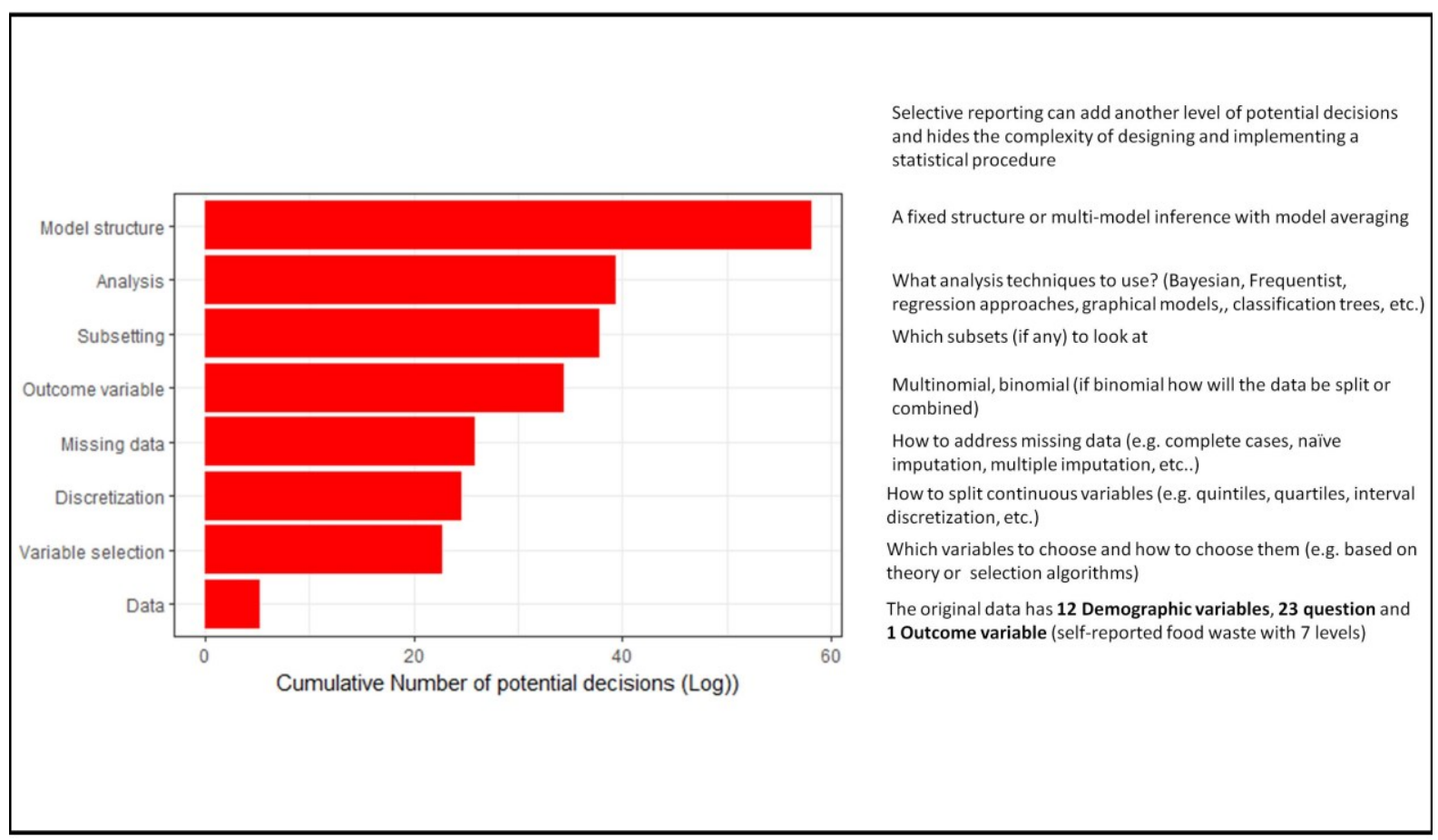

581 Figure 5. An estimation of the cumulative number of potential decisions that a researcher 582 needs to take in order to model the Eurobarometer dataset on food waste. 